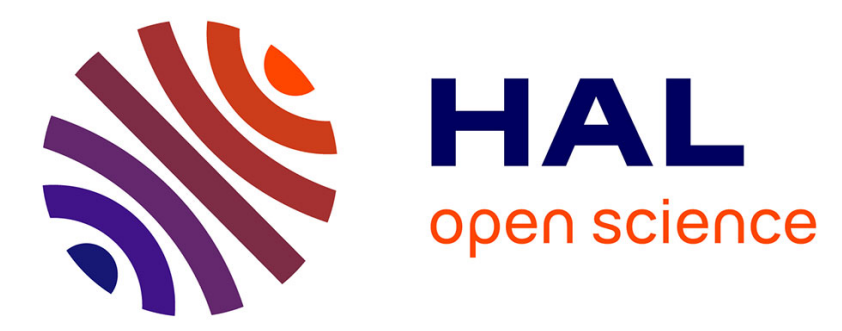

\title{
Pinealectomy and gonadectomy modulate amplitude, but not photoperiodic modulation of Clock gene expression in the Syrian hamster suprachiasmatic nuclei
}

Ibtissam Chakir, Benjamin B Tournier, Hanane Touati, Vincent-joseph Poirel, Etienne Challet, Paul Pevet, Ali Ouarour, Patrick Vuillez

\section{To cite this version:}

Ibtissam Chakir, Benjamin B Tournier, Hanane Touati, Vincent-joseph Poirel, Etienne Challet, et al.. Pinealectomy and gonadectomy modulate amplitude, but not photoperiodic modulation of Clock gene expression in the Syrian hamster suprachiasmatic nuclei. European Journal of Neuroscience, 2021, 53 (11), pp.3612-3620. 10.1111/ejn.15228 . hal-03385094

\author{
HAL Id: hal-03385094 \\ https://hal.science/hal-03385094
}

Submitted on 19 Oct 2021

HAL is a multi-disciplinary open access archive for the deposit and dissemination of scientific research documents, whether they are published or not. The documents may come from teaching and research institutions in France or abroad, or from public or private research centers.
L'archive ouverte pluridisciplinaire HAL, est destinée au dépôt et à la diffusion de documents scientifiques de niveau recherche, publiés ou non, émanant des établissements d'enseignement et de recherche français ou étrangers, des laboratoires publics ou privés. 
doi: 10.1111/ejn.15228. Epub 2021 Apr 27.

Pinealectomy and gonadectomy modulate amplitude, but not photoperiodic modulation of Clock gene expression in the Syrian hamster suprachiasmatic nuclei.

Ibtissam Chakir ${ }^{1,2}$, Benjamin B. Tournier ${ }^{3}$, Hanane Touati ${ }^{4}$, Vincent-Joseph Poirel ${ }^{1}$, Etienne Challet ${ }^{1}$, Paul Pevet ${ }^{1}$, Ali Ouarour ${ }^{5}$, Patrick Vuillez ${ }^{1}$

1, Institute of Cellular and Integrative Neurosciences, CNRS and University of Strasbourg, Strasbourg, France.

2, Multidisciplinary faculty, LPRD, Sultan Moulay Slimane University, Beni-Mellal, Morocco.

3, Division of Adult Psychiatry, Department of Psychiatry, University Hospitals of Geneva, Switzerland.

4, USTHB, Faculty of Biological Sciences, Laboratory of Biology and Physiology of Organisms, Neurobiology Team, BP 32, El Alia, 16111 Bab Ezzouar, Algiers, Algeria.

5, Faculty of Science, Laboratory of Biology and Health, Abdelmalek Essaâdi University, Tetouan, Morocco.

Running title:

Photoperiodic regulation of Clock gene expression

Total number of:

- Pages: 21

- Figures: 4

- Tables: 0

- Equations: 0

Total number of words in:

- The whole manuscript:3840

- The abstract: 249

\section{Keywords.}

biological rhythms, refractory state, clock genes, pineal gland, testis 


\section{Abstract.}

The duration of daytime light phase (photoperiod) controls reproduction in seasonal mammals. Syrian hamsters are sexually active when exposed to long photoperiod, while gonadal atrophy is observed after exposure to short photoperiod. The photorefractory period, or photorefractoriness, is a particular state of spontaneous recrudescence of sexual activity that occurs after a long-term exposure to short photoperiod. Expression of core clock genes in the master circadian clock contained in the suprachiasmatic nuclei depends on photoperiodic conditions. Interestingly, the expression of the Clock gene is also modified in photorefractory Syrian hamsters. Since melatonin and testosterone levels in seasonal species are dependent on photoperiod, photoperiodic variations of Clock mRNA levels in the suprachiasmatic clock could be a consequence of these hormonal changes. To test this hypothesis, we analyzed the effects of pinealectomy on Clock mRNA changes due to long to short photoperiod transition and of gonadectomy on Clock mRNA levels in photorefractory period. Our data show that the suprachiasmatic integration of the short photoperiod (assessed by a rhythmic expression profile of Clock) is independent of the presence of melatonin. Furthermore, constitutively low expression of Clock observed during the photorefractory period does not require the presence of either melatonin or testosterone. However, we show that both hormones provide positive feedback on average levels of Clock expression. Thus, our data support the hypothesis that daily variations of Clock levels in the suprachiasmatic nuclei are influenced by photoperiodic changes and the time spent in short photoperiod, independently of seasonal modifications of melatonin or testosterone levels. 


\section{Introduction}

Seasonal mammals show deep changes in physiology, including reproduction and energy metabolism, according to the photoperiod (i.e., duration of daytime light phase). The nocturnal secretion of melatonin from the pineal gland, which is proportional to the duration of nocturnal phase, plays a critical role in the integration of photoperiodic changes (Pevet, 2003). Among seasonal mammals, Syrian hamsters are called long-day breeders because they are sexually active when exposed to long (summer-like) photoperiod, while regression of the reproductive system, including gonadal atrophy and highly reduced synthesis of sexual hormones, is induced by transfer to short (winter-like) photoperiod. The photorefractory period, or photorefractoriness, is a particular physiological state occurring after a long-term (i.e. over 20 weeks) exposure to a short photoperiod and characterized by a spontaneous recrudescence of gonadal activity, despite the winter-like long-lasting secretion of nocturnal melatonin (Reiter, 1980).

Clock (Circadian locomotor output cycles kaput) is one of the core clock genes of the master circadian clock localized in the suprachiasmatic nuclei (SCN) (Reppert \& Weaver, 2002). The dimer of CLOCK protein, in association with BMAL1, forms the key element of a positive control loop that drives the expression of core clock genes of the negative part of the loops (such as Period (Per)1-3 and Cryptochrome (Cry)1-2) and clock-controlled-genes (such as Avp) (Jin et al., 1999; Reppert \& Weaver, 2002). Expression of Clock in the SCN of nocturnal rodents such as mice and hamsters is most often described as constitutive across 24 h (i.e., with no daily variations). In the case of defective function of Clock, the expression of other clock genes is blunted. The expression rhythm of clock-controlled-genes is abolished, and the daily rhythm of locomotor behavior, a well characterized circadian output of the SCN, is highly disturbed (Jin et al., 1999; Kume et al., 1999; Oishi et al., 2000; Shearman et al., 
2000; Nakamura et al., 2002; Redlin et al., 2005). The endogenous rhythmicity within the SCN is entrained at $24 \mathrm{~h}$ every day by the light/dark cycle (LD). The photic information, carried from the retina to the SCN by the retinohypothalamic tract, is known to regulate the expression of some clock genes, especially from the negative control loop. However, some studies suggested that the CLOCK protein also contributes to the animals' sensitivity to light (Redlin et al., 2005; Ramkisoensing \& Meijer, 2015). From the SCN, the circadian or lightsynchronized signals are then distributed to the whole organism by the autonomous nervous system and by the rhythmic control of hormonal secretion (Challet, 2015). One of the most studied hormones is the pineal melatonin which may participate to the daily synchronization of peripheral oscillators (Pevet \& Challet, 2011; Chakir et al., 2015b).

In addition to the sensitivity to the day-night transitions, expression of clock genes within the SCN and physiology of seasonal species are markedly sensitive to photoperiod changes (Johnston, 2005). Notably, the transfer of Syrian hamsters from long- (LP) to shortphotoperiod (SP) causes a daily rhythmicity of the expression of the Clock gene due to diminished transcription at dawn, and transcriptional modifications of other feedback loops (Tournier et al., 2003; Tournier et al., 2009). Of note, the photoperiodic changes of Clock expression in the SCN are not immediate. Although these changes are already started at 4 days after transfer to SP, the complete SP profile of expression is not yet obtained after 21 days of transfer to SP (Tournier et al., 2009). The photoperiodic signals of SCN are then translated by an increased duration of the nocturnal peak of melatonin, which ultimately leads to a winter-like physiology. One of the simplest photoperiodic indicators to observe is the testicular regression in male hamsters that highlights the period of sexually quiescent of the seasonal reproductive cycle. As mentioned above, a prolonged exposure to SP (over 20 weeks) induces photorefractoriness (i.e. animals become insensitive to the photoperiod, $\mathrm{SP}_{\mathrm{REF}}$ ). During such $\mathrm{SP}_{\mathrm{REF}}$, a spontaneous reversion to a sexually active phenotype of 
spring/summer is observed, which includes testis growth and elevation of testosterone levels (Reiter, 1980). In the SCN, the Clock gene is the only core clock gene to show an altered profile of expression in the photorefractory phase: its daily expression becomes constitutive again, but with lower values as compared to LP (Tournier et al., 2009).

Thus, the Clock gene may be at the heart of the photoperiodic time measurement because it is the only circadian gene in Syrian hamster whose expression is different between LP, SP and $\mathrm{SP}_{\mathrm{REF}}$ conditions. However, the knowledge of the mechanisms underlying its photoperiodic regulation is missing. Because melatonin exerts an action on SCN-driven rhythmicity (Pevet \& Challet, 2011), on the expression of some clock genes in the SCN (Poirel et al., 2003; Johnston et al., 2006; Agez et al., 2009; Nagy et al., 2015; Vriend \& Reiter, 2015) and it may interact with CLOCK (Shimomura et al., 2010), it could also participate in the photoperiodic reading associated with seasonal profiles of Clock expression within the SCN. Testosterone, another hormone known to act on clock genes in the SCN (Iwahana et al., 2008; Karatsoreos et al., 2011; Model et al., 2015) is up-regulated during $\mathrm{SP}_{\mathrm{REF}}$, as aforementioned (Matt \& Stetson, 1979; Tate-Ostroff \& Stetson, 1981; Stetson et al., 1983; Turek et al., 1983). Thus, the distinct profile of Clock expression in $\mathrm{SP}_{\mathrm{REF}}$ could result from the resumption of gonadal activity. Therefore, our study aims to test if changes of the daily expression of Clock in response to SP (winter-like state of gonadal regression) and to prolonged SP (spring-like state of gonadal reactivation) are sensitive to melatonin and testosterone, respectively. 


\section{Material and Methods}

\section{Experimental designs}

Animals were exposed to different artificial photoperiods defined by the lights turning on at ZT0 (zeitgeber time 0) and turning off at different times (ZT16 or ZT8) to create long and short photoperiods.

In the first experiment, animals were either kept in LP (LD16:8, with lights on at 05:00 AM, defining, ZT0) or transferred in a SP (LD8:16, with lights on at 09:00 AM, defining ZT0) for 10- (SP groups) or 30-weeks (photorefractory phase, $\mathrm{SP}_{\mathrm{REF}}$ groups). To test the role of melatonin, animals bred in LP were either pinealectomised (PinX) or sham-operated before the photoperiodic change, thus leading to six groups of twenty-five animals (Fig. 1A).

In the second experiment, animals were kept in SP (LD8:16) for 30-weeks $\left(\mathrm{SP}_{\mathrm{REF}}\right)$. To test the role of testosterone, at the week 17, before spontaneous restoration (Bittman, 1978), animals were gonadectomised and implanted with either empty capsule (GDX) or testosterone-filled capsule (GDX-T), thus, leading to two groups of twenty-five animals per group (Fig. 1B).

The age of individuals at the time of surgery and/or transfer to SP was considered in order that all the animals got the same age (9-10 months) when euthanized at the end of experiments. Whatever the experimental group, animals were weighed and killed by decapitation every $4 \mathrm{~h}$ throughout the $24 \mathrm{~h}$, from ZT $3,7,11,15,19$ to 23 . Brains were quickly removed, frozen in cold $\left(-35^{\circ} \mathrm{C}\right)$ isopentane and stored at $-80^{\circ} \mathrm{C}$ until use. Testeis were dissected and weighed. Plasma was isolated from trunk blood, aliquoted and stored at $-20^{\circ} \mathrm{C}$ until used for testosterone analysis. 


\section{Animals}

Adult male Syrian hamsters (Mesocricetus auratus) were obtained from the colony inbred at the Chronobiotron (animal facility, UMS 3415 CNRS/University of Strasbourg, Strasbourg). Animals were group housed in an environmentally controlled room with a light/dark (LD) 16:8 cycle with a light intensity of approximately 150 lux during daytime and a constant dim red light $(<1$ lux $)$. Temperature was maintained at $20 \pm 1^{\circ} \mathrm{C}$. Animals had free access to food and water. Experimental procedures involving Hamsters complied with the French National law (License 67-88) implementing the European Union Directive 2010/63/EU. All efforts were made to minimize the number of animals used and their suffering, and the study met the ethical standards.

\section{Surgery procedures: pinealectomy, gonadectomy, steroid implants}

In order to perform the pinealectomy, hamsters were anesthetized during the light phase with i.p. injections of a mixture of zoletil 20 (Virbac, Carros, France; $40 \mathrm{mg} / \mathrm{kg}$ i.p.) and rompun 2\% (Bayer Pharma, Puteaux, France; $10 \mathrm{mg} / \mathrm{kg}$ i.p.). After being placed into a stereotaxic instrument (Kopf), a midline circular incision of the skull was gently performed to expose the pineal gland, trying to avoid bleeding of the median venous sinus. The pineal was removed with a pair of fine forceps, the skull cap replaced and the incision closed. After surgery, hamsters were housed individually until complete recovery. For controls, the same steps were made but only half of the midline circular incision of the skull has been done.

Surgical procedure of the gonadectomy was performed under anaesthesia ( $2 \%$ isoflurane in oxygen) and with a mixture of ketamine $(100 \mathrm{mg} / \mathrm{kg}$, i.p.) and rompun $2 \%(10 \mathrm{mg} / \mathrm{kg}$, i.p.). GDX was realised by abdominal incision and removal of both testes. Muscles and fascia were closed using surgical silk, and the overlying skin was closed.

For the steroid implants, silastic capsules (I.D. $1.47 \mathrm{~mm}$, O.D. $1.95 \mathrm{~mm}$, and $13 \mathrm{~mm}$ long; Dow Corning, Belgium), full of testosterone (4-androsten-17 $\beta$-ol-3-one, Sigma, Saint-Louis, 
MO, USA), or empty capsules for controls (Recio et al., 1998). Both were sealed with Silastic glue and allowed to dry overnight. All capsules were primed in a $37^{\circ} \mathrm{C} 0.9 \%$ saline bath for 36h before implantation.

\section{In Situ Hybridization.}

Coronal sections (14- $\mu \mathrm{m}$ thick) covering the rostro-caudal extent of the SCN were cut using a cryostat and mounted onto Superfrost + slides (VWR International, Leuven, Belgium). Slides were then air-dried and stored at $-20^{\circ} \mathrm{C}$ until use. The mouse Clock $(3441 \mathrm{bp})$ clone (generous gift of Prof. J.S. Takahashi, HHMI, University of Texas Southwestern Medical Center, Dallas, USA) was used to synthesize antisense mRNA probes. The synthesis of Clock mRNA probes and the hybridization procedure in Syrian and European hamsters were previously described (Tournier et al., 2003; Tournier et al., 2007; Tournier et al., 2009). Briefly, slides were exposed to antisense Clock probes $\left(54^{\circ} \mathrm{C}\right.$, overnight $)$, then subjected to RNA digestion and treated with stringency washes to remove non-specific probe hybridization. Dehydrated and air-dried slides were exposed to ${ }^{35} \mathrm{~S}$ sensitive films (BioMax MR, Kodak) with ${ }^{14} \mathrm{C}$ standards. All the samples from the first experiment (role of melatonin) were treated simultaneously and blind to the treatment. The same methodology was used for the second experiment (role of testosterone). Relative optical densities (ROD) in bilateral SCN (3 sections per animal) and in the anterior periventricular zone (background signal) were measured using NIH-Image $\mathrm{J}$ after calibration with the standard (Lincoln et al., 2005). The specific signal intensity was defined as follows: $\mathrm{ROD}_{\mathrm{SCN}}-\mathrm{ROD}_{\text {background. }}$ For each animal, values in bilateral SCN were averaged. Analyses were performed by experimenter blind to the treatment group. 


\section{Statistics}

Data are presented as individual values and mean \pm SEM. Data were analysed with one-, two- and three-way analyses of variance (ANOVA) followed by Fisher's least significant difference (LSD) post hoc test using the Statistica software (Statistica 8.0; StatSoft). 


\section{Results}

The experimental designs of experiment 1 and 2 is presented in Figure 1.

\section{Physiological parameters}

The photoperiodic responsiveness was determined from changes in testicular mass, as shown in Figure 2A according to experimental groups. Two-way ANOVA indicated that the testicular mass is under the control of the photoperiod $\mathrm{x}$ treatment interaction $(\mathrm{p}<0.05)$. Post hoc analysis showed that 10 weeks in SP induced a testicular regression as compared to LP (LP-sham vs SP-sham, $\mathrm{p}<0.001)$. Following 30 weeks in SP, the testicular mass became again very close to the LP group ( $\mathrm{SP}_{\mathrm{REF}}$-sham vs LP, $\left.\mathrm{p}>0.05\right)$. Pinealectomy did not modify the testicular mass in LP (LP-sham vs LP-PinX, p>0.05). Importantly, pinealectomy completely abolished the regression induced by the short photoperiod (SP-sham vs SP-PinX, $\mathrm{p}<0.001$ ). Therefore, no difference in testicular mass was observed between sham- and pinealectomizedanimals placed during 30 weeks in $\mathrm{SP}\left(\mathrm{SP}_{\mathrm{REF}}\right.$-sham vs $\left.\mathrm{SP}_{\mathrm{REF}}-\mathrm{PinX}, \mathrm{p}>0.05\right)$, as $\mathrm{SP}_{\mathrm{REF}}-\mathrm{PinX}$ did not have testicular regression.

In addition, the seminal vesicle mass was measured as an indicator of testosterone presence (Fig. 2B). The one-way ANOVA indicated the main effect of the group on seminal vesicle mass $(\mathrm{p}<0.001)$. Post hoc test showed significant reductions in seminal vesicle mass in the SP-sham and GDX as compared to LP and GDX-T groups $(\mathrm{p}<0.001)$, validating low testosterone level in SP-sham and GDX and its restoration in GDX-T as compared to LP.

\section{Effects of melatonin and photoperiod on Clock expression (experiment 1)}

The effects of photoperiod, pinealectomy and ZT on Clock mRNA levels are presented in Figure 3.

Three-way ANOVA indicated significant main effects of photoperiod $(p<0.001)$, pinealectomy $(\mathrm{p}<0.001)$ and ZT $(\mathrm{p}<0.01)$. Although the mean Clock mRNA levels were 
influenced by the pinealectomy $(-10.07 \pm 2.25 \%$, $<<0.001$; ROD values, Sham-treated: $4.5 \pm$ 2.25, PinX: $3.4 \pm 2$ ), this effect was independent of both photoperiod and ZT (pinealectomy $\mathrm{X}$ ZT x photoperiod interaction: $\mathrm{p}>0.05$; pinealectomy $\mathrm{x}$ ZT interaction: $\mathrm{p}>0.05$; pinealectomy $\mathrm{x}$ photoperiod interaction: $\mathrm{p}>0.05$ ). Thus, pinealectomy did not prevent the appearance of a ZT effect in specific profile of Clock mRNA expression in $\mathrm{SP}$ and $\mathrm{SP}_{\mathrm{REF}}$ (Figure 3A-B).

Independently of the pinealectomy, the expression of Clock mRNA was constitutive in LP (ZT effect: $p>0.05$, Figure 3C). In marked contrast, exposition of animals to 10 weeks of SP (SP-sham and SP-PinX) induced a significant decrease in Clock mRNA levels at ZT15, ZT19 and ZT23, as compared to LP ( $<<0.05$, Figure 3C). Finally, the expression of Clock mRNA was constitutive in $\mathrm{SP}_{\mathrm{REF}}\left(\mathrm{SP}_{\mathrm{REF}}\right.$-sham and $\mathrm{SP}_{\mathrm{REF}}$-PinX, $\mathrm{ZT}$ effect: $\left.\mathrm{p}>0.05\right)$ as an additional decrease in Clock mRNA levels was observed at ZT3, ZT7 and ZT11, as compared to SP (SPsham and SP-PinX, Figure 3C). Thus, mean levels of Clock mRNA in SP $\mathrm{REF}_{\text {were }}$ significantly decreased as compared to LP $(-24.08 \pm 2.29 \% ; \mathrm{p}<0.001$, Figure $3 \mathrm{D}$; ROD values, LP: $4.5 \pm 2.25, \mathrm{SP}_{\mathrm{REF}}: 3.4 \pm 2$ ). Representative examples of the expression of Clock at high, intermediate and low levels are given in the Figure 3E.

Effects of testosterone on Clock gene in $S P_{R E F}$ (experiment 2)

Two-way ANOVA revealed the absence of ZT effect $(p>0.05)$ and of the ZT $x$ gonadectomy interaction $(\mathrm{p}>0.05)$, indicating that gonadectomy did not prevent the occurrence of a constitutive expression profile of Clock mRNA in $\mathrm{SP}_{\mathrm{REF}}$ (Figure 4A). However, a significant main effect of gonadectomy $(\mathrm{p}<0.01)$ was observed. Gonadectomy induced a decrease in Clock mRNA levels as compared to $\operatorname{SP}_{\mathrm{REF}}(-26.11 \pm 3.70 \%$; $<<0.001$; ROD values, $\mathrm{SP}_{\mathrm{REF}}: 4.5 \pm 2.25$, GDX: $3.4 \pm 2$ ) that was reversed by testosterone implants ($5.77 \pm 4.53 \% ; \mathrm{p}>0.05$, Figure 4B; ROD values, $\mathrm{SP}_{\mathrm{REF}}: 4.5 \pm 2.25, \mathrm{GDX}-\mathrm{T}: 3.4 \pm 2$ ). 


\section{Discussion}

The present study shows that the daily profile of Clock expression in the SCN is not only a marker of the photoperiod, but also of the duration spent in the winter day-length condition. From constitutively high levels in LP, Clock mRNA expression becomes rhythmic in SP and shows constitutively low levels when reproductive physiology escapes the inhibitory action of the $\mathrm{SP}$ (i.e. $\mathrm{SP}_{\mathrm{REF}}$ ). In addition, the pinealectomy, known to inhibit physiological integration of SP (such a regression of the gonads), did not prevent neither the appearance of the rhythmicity of expression of the Clock gene in SP nor the presence of constant and low levels of Clock mRNA in $\mathrm{SP}_{\mathrm{REF}}$. In fact, pinealectomized animals showed daily expression profiles of Clock comparable to sham-treated animals in both $\mathrm{SP}$ and in $\mathrm{SP}_{\mathrm{REF}}$. In animals placed in SP with testicular regression, the gonadectomy did not inhibit the Clock mRNA changes in $\mathrm{SP}_{\mathrm{REF}}$, as compared to SP. Thus, changes in Clock mRNA expression induced by SP and by the duration spent in SP seems to be independent of the presence of two main hormones involved in the seasonal physiology, namely melatonin and testosterone. Our data suggest that photoperiodic modulation of Clock levels in the master clock occurs upstream of the variations of activity of the pineal and gonads, and not as a consequence of feedback effects of their respective hormones.

We showed that melatonin, a key hormone in seasonal physiology, does not participate in the photoperiodic adaptation of Clock gene expression. This observation, which corroborates the absence of effect of pinealectomy on the increased light sensitivity phase in terms of $c$-fos after transfer to SP (Vuillez et al. 1996), suggests that the photoperiodic integration by the SCN is insensitive to melatonin. Indeed, although the pinealectomized animals have an inhibited physiological integration of SP (i.e. testicular regression cannot be longer induced by the long-lasting melatonin signal), they show a daily expression profile of Clock mRNA level that normally corresponds to winter-like SP conditions. Thus, the adaptation of Clock 
mRNA levels from LP to SP seems to be a direct response to the changes of photic signals and could therefore participate in the development of a daily synchronization message depending on the photoperiodic information. In agreement with this hypothesis, the expression of clock-controlled genes within SCN is also dependent on the photoperiod, but with a delay of adaptation greater than 21 days (Tournier et al., 2009). In contrast, we showed that melatonin, whatever the photoperiod, may induce an increase in Clock mRNA levels, which could contribute to a strengthened functioning of the master clock. Therefore, our observation corroborates and extends previous data on the effects of melatonin on gene expression within SCN.

During the photorefractory period, reproductive physiology escapes the inhibitory action of prolonged secretion of nocturnal melatonin associated to short days. Pinealectomy performed before the transfer from LP to SP, however, had no effect on the reduction of Clock mRNA levels observed in $\mathrm{SP}_{\mathrm{REF}}$ as compared to LP. However, as the desensitization of gonadal axis to melatonin in $\mathrm{SP}_{\mathrm{REF}}$ induces a re-increase in testosterone levels, and as testosterone can act on the SCN (Karatsoreos et al, 2007; Model et al, 2017), we tested if the acquisition of the Clock mRNA expression profile in $\mathrm{SP}_{\mathrm{REF}}$ depends on the presence of gonadal activity. We showed that testosterone does not modify photoperiodic time integration. However, testosterone showed a positive effect on Clock mRNA levels. Thus, although melatonin and testosterone act increase on Clock mRNA levels, they do not participate in photoperiodic control of its rhythmic or constitutive expression in the SCN.

The modifications of the expression of Clock according to the photoperiodic conditions we showed confirm previous studies. SP induces a decrease in the amount of Clock mRNA at the end of the night in Syrian hamsters housed in LD10:14 or LD8:16 (Tournier et al., 2003; Tournier et al., 2009). It is interesting to note that the duration during which Clock mRNA levels are low appears to be greater when the animals are placed in LD8:16 (from ZT15 to 
ZT23 in the present study and from ZT14 to ZT2 in the study published in 2009) than in LD10:14 (from ZT23 to ZT5). This observation must remain a hypothesis because the number of samples taken over 24 hours is different between studies (every 4 hours in the studies in LD8:16 and every 2 hours in the study in LD10:14) and therefore does not allow a direct comparison. Thus, our study confirms the appearance of a rhythm in the daily expression of Clock in $\mathrm{SP}$ and its abolition in $\mathrm{SP}_{\mathrm{REF}}$ and extended the previous observations by showing that these adaptations are independent of the presence of melatonin (appearance of the rhythmic Clock mRNA expression in SP) and testosterone (disappearance of the rhythmic Clock mRNA expression after a prolonged time in SP). Overall these adaptations go in the direction of reducing Clock mRNA levels in $\mathrm{SP}$ and $\mathrm{SP}_{\mathrm{REF}}$. In the European hamster, a reduction in Clock mRNA levels were also observed but without the appearance of a rhythmic expression. However, the physiology of the European hamster is sensitive to the photoperiod but also to another endogenous timer, the so-called circannual clock (Canguilhem et al., 1988; MassonPevet et al., 1994). In addition, the study showing SP-induced reduction in Clock mRNA levels in the European hamster without the appearance of a rhythm was performed in natural photoperiod. These two fundamental differences make it difficult to directly compare the conclusions of these studies, but it is important to note that in both Syrian and European hamsters, an overall decrease in Clock levels is observed. Conversely, these changes are less pronounced in non-photoperiodic animals, whose reproductive physiology is insensitive to photoperiod changes (Sumova et al., 2003).

Thus, in all of these studies, the SP induced a decrease in the quantities of Clock mRNA. However, the effects of SP seem to be different over the daily time: (i) after a short time exposure in SP (less than 1 week), levels are only decreased at the night / day transition; (ii) when the winter-like physiology is in place ( 8 weeks), the decrease extends to the dark phase 
of the day; (iv) and finally, when the spontaneous return to a summer-like physiology takes place, the levels are low even at the day / night transition. The consequence of the appearance of Clock level alterations as a function of the photoperiod and of the time spent in SP seems to indicate that Clock represents a seasonal timer, independent of the feedback of two hormones closely related to seasonal physiology (i.e. melatonin and testosterone). The rapid or otherwise slower impact of SP on Clock levels at the day/night and night/day transition, respectively, could contribute to the day-to-day elaboration of a photoperiod-dependent circadian message which would also depend on the duration spent in the short photoperiod. Thus, expression patterns of Clock mRNA could, to some extent, be markers of the photoperiod, in response to photic stimuli and independent of the hormonal feedback.

Another important issue to address is the species differences of Clock expression in the SCN. Clock seems to be of constitutive expression in nocturnal rodents such as rats (Sumova et al., 2003), Syrian (Tournier et al., 2009) and European hamsters (Tournier et al., 2007), when placed in LP. On the contrary, its levels vary throughout the day in the SCN of diurnal species (rodent: (Chakir et al., 2015a); and sheep: (Lincoln et al., 2002)). In addition, adaptations of its expression to a change in photoperiod are also described as speciesdependent with the maintenance of a rhythm of expression (Lincoln et al., 2002), its appearance (Tournier et al., 2009) or a simple decrease in its average levels (Tournier et al., 2007). These evidences for species-specific clock gene expression patterns in LP and in response to a transfer to SP sustain the hypothesis that Clock gene could participate in the physiological differences observed between mammals at both the daily and annual levels.

As a conclusion, our data clearly demonstrate that pinealectomy did not affect the SPinduced appearance of rhythmic Clock expression and the abolishment of such rhythm in $\mathrm{SP}_{\mathrm{REF}}$. In addition, the gonadectomy and testosterone supply did not affect the specific Clock expression pattern in $\mathrm{SP}_{\mathrm{REF}}$. Our data support the hypothesis that expression of Clock gene in 
the $\mathrm{SCN}$ is a time-counter sensitive to photoperiod changes. Further experiments will be necessary to identify if this differential regulation can be transferred to circadian oscillations outside of the SCN and how it can participate in physiological changes controlled by photoperiodism.

\section{Acknowledgements}

We thank Pr. J.S. Takahashi (HHMI, University of Texas Southwestern Medical Center, Dallas, USA) for the gift of $m$ Clock clone.

\section{Competing Interests}

Authors have nothing to disclose.

\section{Author Contributions}

IC, BBT, EC, PP, PV designed the experiment.

IC, PV, HT, V-JP performed the experiment.

IC, BBT, EC, PP, PV analyzed and interpreted the data.

IC, BBT, EC, PP, PV wrote the article and AO revised it.

\section{Data accessibility}

Raw data are available from the corresponding author on request.

\section{Abbreviations}

GDX: gonadectomy; GDX-T: gonadectomy plus testosterone-filled capsule; LD: light/dark cycle; LP: long photoperiod; PinX: pinealectomy; SCN: suprachiasmatic nuclei; SP: short photoperiod; $\mathrm{SP}_{\mathrm{REF}}$ : photorefractoriness due to prolonged exposure to $\mathrm{SP}$. 


\section{References.}

Agez, L., Laurent, V., Guerrero, H.Y., Pevet, P., Masson-Pevet, M. \& Gauer, F. (2009) Endogenous melatonin provides an effective circadian message to both the suprachiasmatic nuclei and the pars tuberalis of the rat. J Pineal Res, 46, 95-105.

Canguilhem, B., Vaultier, J.P., Pevet, P., Coumaros, G., Masson-Pevet, M. \& Bentz, I. (1988) Photoperiodic regulation of body mass, food intake, hibernation, and reproduction in intact and castrated male European hamsters, Cricetus cricetus. J Comp Physiol A, $163,549-557$.

Chakir, I., Dumont, S., Pevet, P., Ouarour, A., Challet, E. \& Vuillez, P. (2015a) The circadian gene Clock oscillates in the suprachiasmatic nuclei of the diurnal rodent Barbary striped grass mouse, Lemniscomys barbarus: a general feature of diurnality? Brain Res, 1594, 165-172.

Chakir, I., Dumont, S., Pevet, P., Ouarour, A., Challet, E. \& Vuillez, P. (2015b) Pineal melatonin is a circadian time-giver for leptin rhythm in Syrian hamsters. Front Neurosci, 9, 190.

Challet, E. (2015) Keeping circadian time with hormones. Diabetes Obes Metab, 17 Suppl 1, 76-83.

Iwahana, E., Karatsoreos, I., Shibata, S. \& Silver, R. (2008) Gonadectomy reveals sex differences in circadian rhythms and suprachiasmatic nucleus androgen receptors in mice. Horm Behav, 53, 422-430.

Jin, X., Shearman, L.P., Weaver, D.R., Zylka, M.J., de Vries, G.J. \& Reppert, S.M. (1999) A molecular mechanism regulating rhythmic output from the suprachiasmatic circadian clock. Cell, 96, 57-68.

Johnston, J.D. (2005) Measuring seasonal time within the circadian system: regulation of the suprachiasmatic nuclei by photoperiod. J Neuroendocrinol, 17, 459-465.

Johnston, J.D., Tournier, B.B., Andersson, H., Masson-Pevet, M., Lincoln, G.A. \& Hazlerigg, D.G. (2006) Multiple effects of melatonin on rhythmic clock gene expression in the mammalian pars tuberalis. Endocrinology, 147, 959-965.

Karatsoreos, I.N., Butler, M.P., Lesauter, J. \& Silver, R. (2011) Androgens modulate structure and function of the suprachiasmatic nucleus brain clock. Endocrinology, 152, 19701978.

Kume, K., Zylka, M.J., Sriram, S., Shearman, L.P., Weaver, D.R., Jin, X., Maywood, E.S., Hastings, M.H. \& Reppert, S.M. (1999) mCRY1 and mCRY2 are essential components of the negative limb of the circadian clock feedback loop. Cell, 98, 193205.

Lincoln, G., Messager, S., Andersson, H. \& Hazlerigg, D. (2002) Temporal expression of seven clock genes in the suprachiasmatic nucleus and the pars tuberalis of the sheep: 
evidence for an internal coincidence timer. Proc Natl Acad Sci U S A, 99, 1389013895.

Lincoln, G.A., Johnston, J.D., Andersson, H., Wagner, G. \& Hazlerigg, D.G. (2005) Photorefractoriness in mammals: dissociating a seasonal timer from the circadianbased photoperiod response. Endocrinology, 146, 3782-3790.

Masson-Pevet, M., George, D., Kalsbeek, A., Saboureau, M., Lakhdar-Ghazal, N. \& Pevet, P. (1994) An attempt to correlate brain areas containing melatonin-binding sites with rhythmic functions: a study in five hibernator species. Cell Tissue Res, 278, 97-106.

Matt, K.S. \& Stetson, M.H. (1979) Hypothalamic-pituitary-gonadal interactions during spontaneous testicular recrudescence in golden hamsters. Biol Reprod, 20, 739-746.

Model, Z., Butler, M.P., LeSauter, J. \& Silver, R. (2015) Suprachiasmatic nucleus as the site of androgen action on circadian rhythms. Horm Behav, 73, 1-7.

Nagy, A.D., Iwamoto, A., Kawai, M., Goda, R., Matsuo, H., Otsuka, T., Nagasawa, M., Furuse, M. \& Yasuo, S. (2015) Melatonin adjusts the expression pattern of clock genes in the suprachiasmatic nucleus and induces antidepressant-like effect in a mouse model of seasonal affective disorder. Chronobiol Int, 32, 447-457.

Nakamura, W., Honma, S., Shirakawa, T. \& Honma, K. (2002) Clock mutation lengthens the circadian period without damping rhythms in individual SCN neurons. Nat Neurosci, 5, 399-400.

Oishi, K., Fukui, H. \& Ishida, N. (2000) Rhythmic expression of BMAL1 mRNA is altered in Clock mutant mice: differential regulation in the suprachiasmatic nucleus and peripheral tissues. Biochem Biophys Res Commun, 268, 164-171.

Pevet, P. (2003) Melatonin: from seasonal to circadian signal. J Neuroendocrinol, 15, $422-$ 426.

Pevet, P. \& Challet, E. (2011) Melatonin: both master clock output and internal time-giver in the circadian clocks network. J Physiol Paris, 105, 170-182.

Poirel, V.J., Boggio, V., Dardente, H., Pevet, P., Masson-Pevet, M. \& Gauer, F. (2003) Contrary to other non-photic cues, acute melatonin injection does not induce immediate changes of clock gene mRNA expression in the rat suprachiasmatic nuclei. Neuroscience, 120, 745-755.

Ramkisoensing, A. \& Meijer, J.H. (2015) Synchronization of Biological Clock Neurons by Light and Peripheral Feedback Systems Promotes Circadian Rhythms and Health. Front Neurol, 6, 128.

Redlin, U., Hattar, S. \& Mrosovsky, N. (2005) The circadian Clock mutant mouse: impaired masking response to light. J Comp Physiol A Neuroethol Sens Neural Behav Physiol, 191, 51-59. 
Reiter, R.J. (1980) The pineal and its hormones in the control of reproduction in mammals. Endocr Rev, 1, 109-131.

Reppert, S.M. \& Weaver, D.R. (2002) Coordination of circadian timing in mammals. Nature, 418, 935-941.

Shearman, L.P., Sriram, S., Weaver, D.R., Maywood, E.S., Chaves, I., Zheng, B., Kume, K., Lee, C.C., van der Horst, G.T., Hastings, M.H. \& Reppert, S.M. (2000) Interacting molecular loops in the mammalian circadian clock. Science, 288, 1013-1019.

Shimomura, K., Lowrey, P.L., Vitaterna, M.H., Buhr, E.D., Kumar, V., Hanna, P., Omura, C., Izumo, M., Low, S.S., Barrett, R.K., LaRue, S.I., Green, C.B. \& Takahashi, J.S. (2010) Genetic suppression of the circadian Clock mutation by the melatonin biosynthesis pathway. Proc Natl Acad Sci US A, 107, 8399-8403.

Stetson, M.H., Watson-Whitmyre, M. \& Tate-Ostroff, B. (1983) Role of the pineal and its hormone melatonin in the termination of photorefractoriness in golden hamsters. Biol Reprod, 29, 689-696.

Sumova, A., Jac, M., Sladek, M., Sauman, I. \& Illnerova, H. (2003) Clock gene daily profiles and their phase relationship in the rat suprachiasmatic nucleus are affected by photoperiod. J Biol Rhythms, 18, 134-144.

Tate-Ostroff, B. \& Stetson, M.H. (1981) Correlative changes in the response to castration and the onset of refractoriness in male golden hamsters. Neuroendocrinology, 32, 325-329.

Tournier, B.B., Birkenstock, J., Pevet, P. \& Vuillez, P. (2009) Gene expression in the suprachiasmatic nuclei and the photoperiodic time integration. Neuroscience, $\mathbf{1 6 0}$, 240-247.

Tournier, B.B., Dardente, H., Simonneaux, V., Vivien-Roels, B., Pevet, P., Masson-Pevet, M. \& Vuillez, P. (2007) Seasonal variations of clock gene expression in the suprachiasmatic nuclei and pars tuberalis of the European hamster (Cricetus cricetus). Eur J Neurosci, 25, 1529-1536.

Tournier, B.B., Menet, J.S., Dardente, H., Poirel, V.J., Malan, A., Masson-Pevet, M., Pevet, P. \& Vuillez, P. (2003) Photoperiod differentially regulates clock genes' expression in the suprachiasmatic nucleus of Syrian hamster. Neuroscience, 118, 317-322.

Turek, F.W., Losee-Olson, S.H. \& Ellis, G.B. (1983) Pinealectomy and lesions of the suprachiasmatic nucleus affect the castration response in hamsters exposed to short photoperiods. Neuroendocrinology, 36, 335-339.

Vriend, J. \& Reiter, R.J. (2015) Melatonin feedback on clock genes: a theory involving the proteasome. J Pineal Res, 58, 1-11.

Vuillez, P., Jacob, N., Teclemariam-Mesbah, R. \& Pévet P. (1996) In Syrian an European hamsters, the duration of sensitive phase to ligtht of the suprachiasmatic nuclei depends on the photoperiod. Neurosci. Lett. 208, 37-40. 


\section{Figures and Figure legends}

\section{Figure 1. Experimental design.}

The solid line curve illustrates the time course of the regression and the spontaneous restoration of sexual activity observed in hamsters transferred from long photoperiod (LP) to short photoperiod (SP). SP induces sexual inhibition within 10 weeks. Nevertheless, hamsters kept in SP for longer time (30 weeks) are refractory to $\mathrm{SP}\left(\mathrm{SP}_{\mathrm{REF}}\right)$ and restore a spring physiology. Name of each group is written in italic, close to a circle whose position show the time of euthanasia as well as sexual physiological state. A. in experiment 1 , animals were either pinealectomized (Pin-X) or Sham operated few days before transfer into SP and were euthanized after 10 weeks or 30 weeks passed in SP. Two other groups (Pin-X and sham hamsters) were maintained in LP 10 weeks before euthanasia. B. In experiment 2, animals were transferred into SP for testis regression. After 17 weeks, they were gonadectomised before spontaneous restoration and i.p. implanted with either empty capsule (GDX) or testosterone filled capsule (GDX-T).

\section{Figure 2. Physiological validation of the experimental procedures.}

A. Animals were pinealectomized (PinX) or sham-operated (sham) and bred in LP or transferred in SP for 10 weeks (SP) or 30 weeks $\left(\mathrm{SP}_{\mathrm{REF}}\right)$. At the end, the testicular mass was measured. Significantly different from the LP group at $\star \star \star \mathrm{p}<0.001$ using a two-way ANOVA followed by a LSD post hoc test. B. The seminal vesicle mass was measured in all experimental groups. Significantly different from the LP group at $\star \star \star p<0.001$ and from the GDX-T group at $\infty \infty \infty \mathrm{p}<0.001$ using a one-way ANOVA followed by a LSD post hoc test.

\section{Figure 3. Effects of melatonin and photoperiod on Clock gene expression in the master clock.}

Clock mRNA levels in the SCN of animals bred in long photoperiod LD16:8 (LP, pink circles) or short photoperiod LD8:16 for 10- (SP, green squares) or 30-weeks ( $\mathrm{SP}_{\mathrm{REF}}$, grey triangles). A-C. Data present shamoperated (sham, A) pinealectomized (PinX, B) or both groups (C). Data are presented in reference to ZT0 (i.e., lights on) in each condition and expressed in relative optical density (ROD). Significant differences between LP and SP groups at $\star \mathrm{p}<0.05$ and between $\mathrm{SP}$ and $\mathrm{SP}_{\mathrm{REF}}$ groups at $\infty \mathrm{p}<0.05$ using a two-way ANOVA followed by a LSD post hoc test. D. Values are also presented independently of the ZT. Significant differences between LP groups (Sham and PinX) and $\mathrm{SP}_{\mathrm{REF}}$ groups (Sham and PinX) at $\star \mathrm{p}<0.05$ using a two-way ANOVA followed by a LSD post hoc test. E. Representative examples of maximal, intermediate and minimal expression of Clock 
gene in the suprachiasmatic nuclei. Individual examples were taken from one animal at ZT15 in the LP-sham group (high level), at ZT3 in the LP-sham group (intermediate level) and at ZT19 in the SP-PinX group (low level). Scale bar: $2 \mathrm{~mm}$.

Figure 4. Regulation of Clock gene expression within the master clock under $\mathrm{SP}_{\mathrm{REF}}$ by testosterone.

Clock mRNA levels in the SCN of animals bred in short photoperiod LD8:16 for 30-weeks $\left(\mathrm{SP}_{\mathrm{REF}}\right.$, grey triangles). After 17 weeks in SP, one part of the animals was gonadectomized and implanted with either empty capsule (GDX, orange squares) or testosterone-filled capsule (GDX-T, black circles). A. Data are presented in reference to ZT0 (i.e., lights on) in each condition and expressed in relative optical density (ROD). B. Values are presented independently of the ZT. Significantly different from the $\mathrm{SP}_{\mathrm{REF}}$ group at $\star \star \mathrm{p}<0.01$ using a two-way ANOVA followed by a LSD post hoc test. 

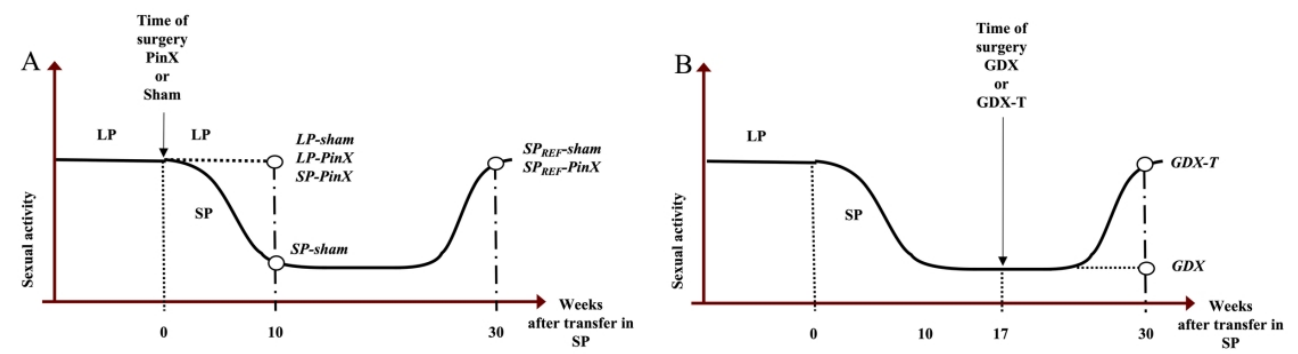

$211 \times 59 \mathrm{~mm}(300 \times 300 \mathrm{DPI})$ 

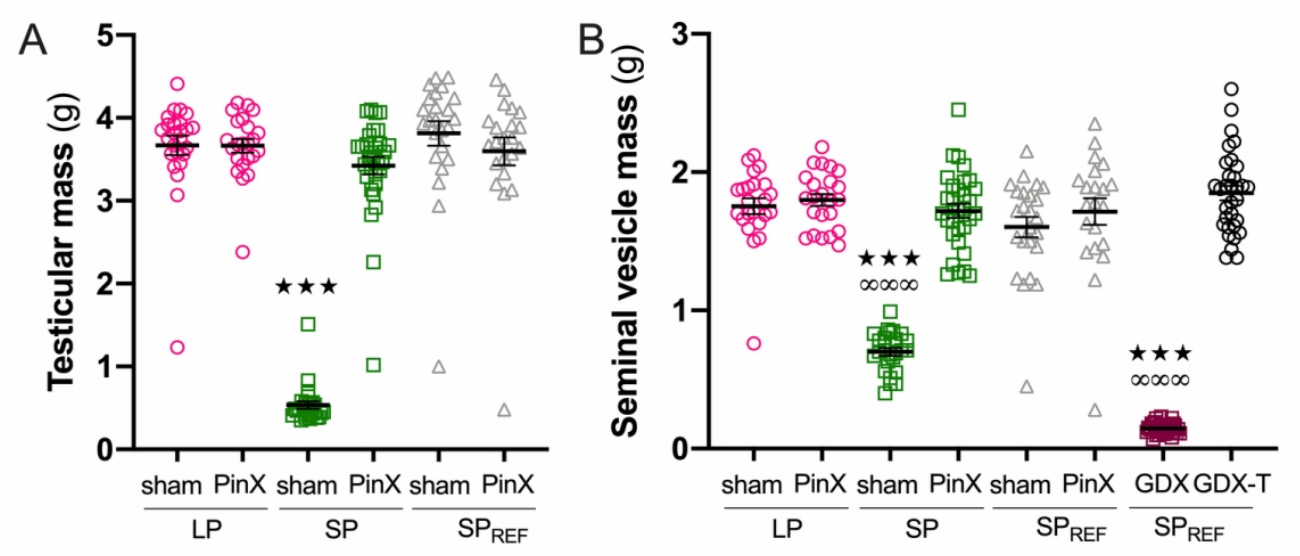

$128 \times 59 \mathrm{~mm}(300 \times 300 \mathrm{DPI})$ 

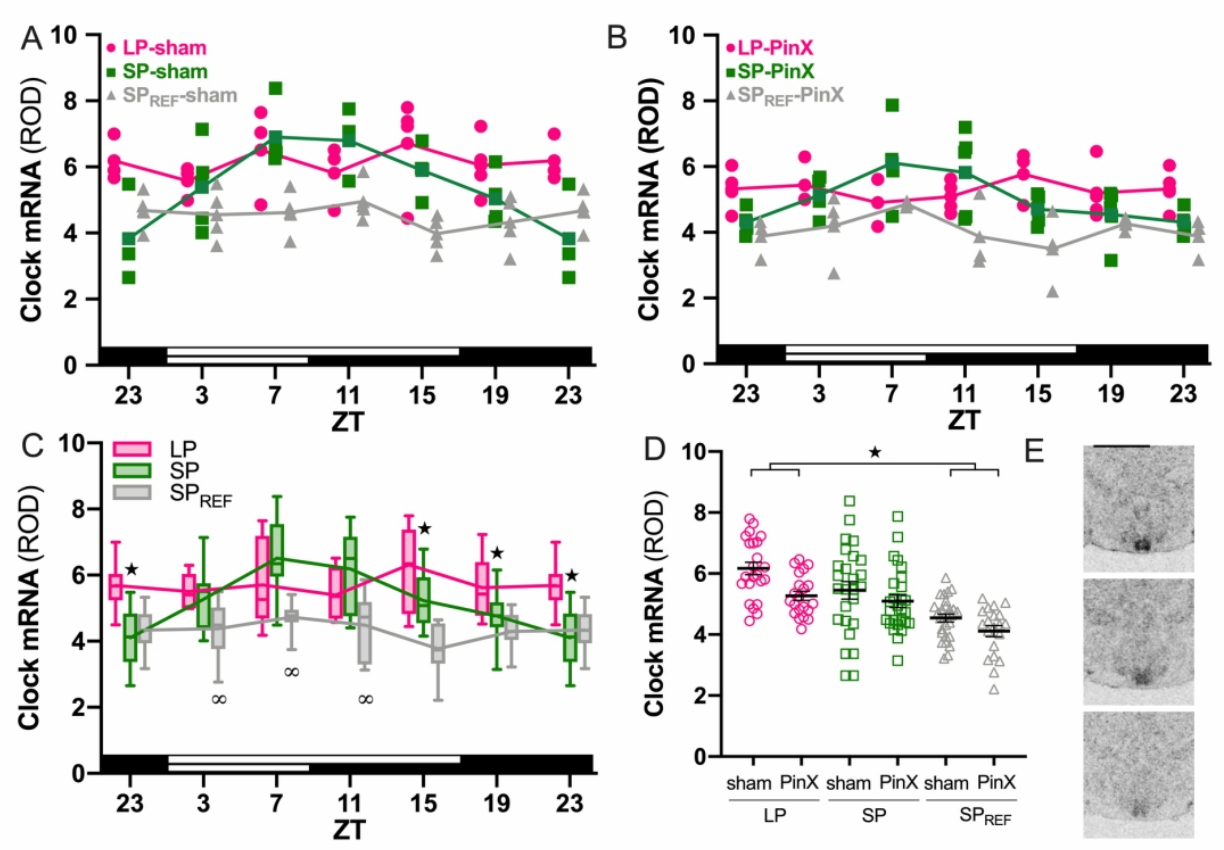

$168 \times 114 \mathrm{~mm}(300 \times 300$ DPI $)$ 


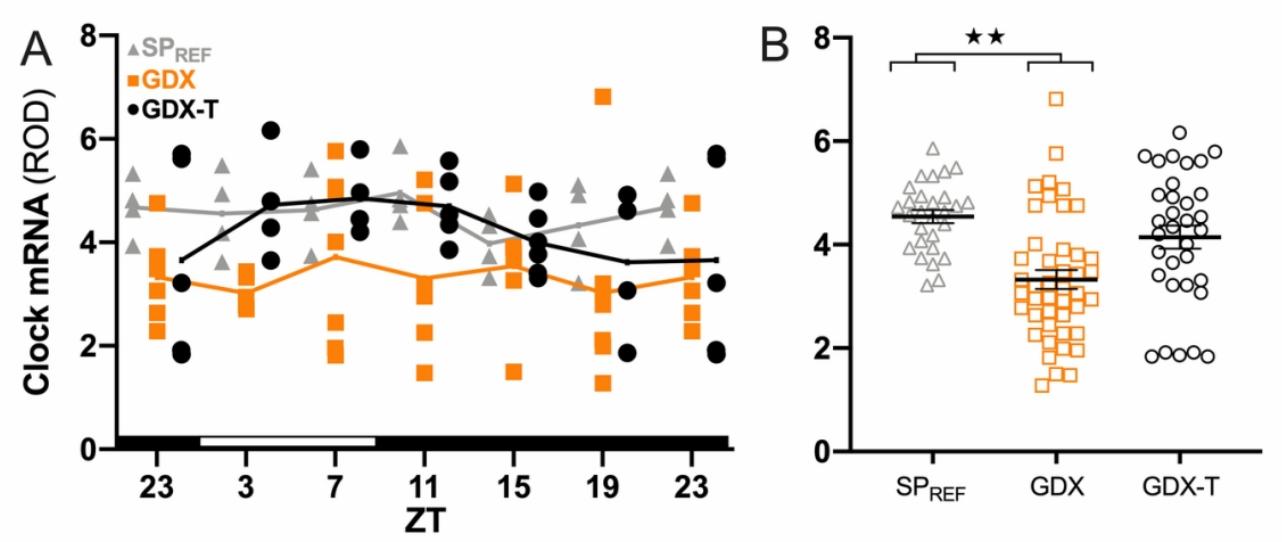

$115 \times 53 \mathrm{~mm}(300 \times 300$ DPI $)$ 
Graphical abstract (73/75)

Within the hamster master clock, expression rhythm of Clock gene in response to transfer from long- (LP) to short-photoperiod (SP) is melatonin independent. Alterations in Clock mRNA levels during the photorefractory period $\left(\mathrm{SP}_{\mathrm{REF}}\right)$ are also testosterone independent. However, the average Clock mRNA amount is lower in the absence of both hormones. Thus, the photoperiodic control of daily variations of Clock gene is independent of the positive melatonin/testosterone feedback signals. GDX: gonadectomy; PinX: Pinealectomy 


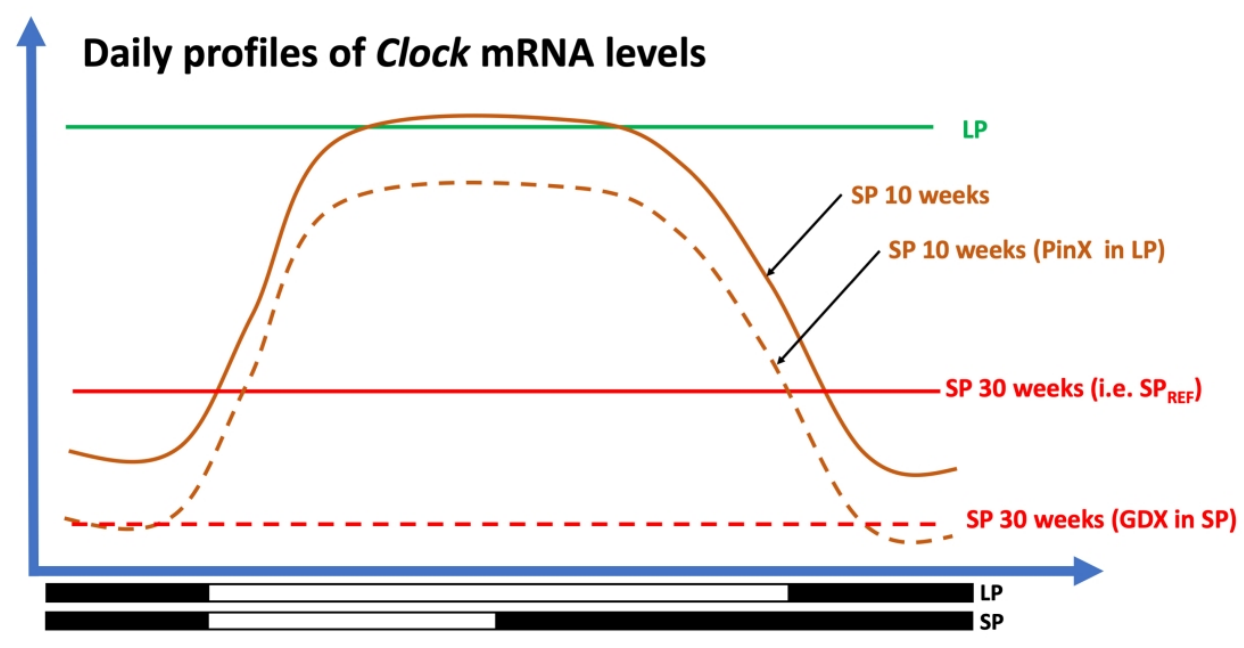

$338 \times 190 \mathrm{~mm}(225 \times 225 \mathrm{DPI})$ 